\title{
Introducing direction fields to students learning ordinary differential equations (ODEs) through guided inquiry
}

Diarmaid Hyland ${ }^{\mathrm{a}, \mathrm{b} *}$, Paul van Kampen ${ }^{\mathrm{a}}$, and Brien Nolan ${ }^{\mathrm{b}}$

${ }^{a}$ School of Physical Sciences, Dublin City University, Dublin, Ireland; ${ }^{b}$ School of Mathematical Sciences, Dublin City University, Dublin, Ireland.

Email address of corresponding author: Diarmaid.hyland3@mail.dcu.ie

Email address of other authors: Paul.van.kampen@dcu.ie Brien.nolan@dcu.ie

ORCID Identifiers:

Paul van Kampen: orcid.org/0000-0003-3043-8110

Brien Nolan: orcid.org/0000-0002-9356-6833

Diarmaid Hyland: orcid.org/0000-0003-3787-5153 


\section{Introducing direction fields to students learning ordinary differential equations (ODEs) through guided inquiry}

This paper reports on an intervention as part of which direction fields were introduced to students learning ordinary differential equations (ODEs). The intervention was designed and implemented to address issues with students' conceptions of the solutions of ODEs. These were identified by a diagnostic survey and through a review of the literature. The intervention comprised fifteen guided inquiry tutorials, one of which introduced students to direction fields in the context of first order ODEs. A combination of interviews and immediate and delayed post-testing was used to measure the impact of the tutorial. The design of the tutorial and the results of the interviews and post-test data are reported. A large majority of the students who completed the tutorial were able to successfully complete tasks linking direction fields to their study of ODEs. A significant improvement was also observed in relation to students' conceptions of solutions to an ODE.

Keywords: differential equations; direction fields; solutions to differential equations; guided inquiry. 


\section{Introduction and background}

This paper reports on a study of an intervention that comprises a guided inquiry tutorial on direction fields (also known as slope fields or quiver plots) designed and implemented as part of a service mathematics module on Ordinary Differential Equations (ODEs) taken by physics undergraduates and undergraduate prospective mathematics teachers in an Irish university. In a previous paper [1] we reported that, pre-intervention, students who had completed the module possessed fragmented concept images of ODEs. Particularly, important issues such as what defines an ODE and what is meant by a solution to an ODE were not well understood by students. These results have led us to develop an intervention that focuses less on procedural fluency and more on conceptual understanding, as advocated by various authors [2-6].

Habre's work $[3,4]$ provides early examples of the study of using graphical or geometric approaches to solving differential equations in an educational context. Stephan and Rasmussen [7] describe a reform setting in which they engaged students in situations where they constructed graphical, numerical, and analytical techniques simultaneously and re-created the notion of direction fields in a bottom-up manner. By careful implementation, the introduction of graphs as one of a number of external representations may improve students' conceptual understanding [8, 9], particularly with respect to their conception of solutions to ODEs, which has been the focus of much of the research on ODEs to date [10-15].

The effect of a change in pedagogy on conceptual understanding of ODEs has also been studied extensively [16-20]. Generally speaking, constructivist approaches have been shown to be potentially beneficial. The findings of our survey and the literature described above motivated us to develop an intervention for our students. The purpose of the intervention was to enrich students' concept image of ODEs by focusing on several major themes. Among these themes was the notion of solutions of an ODE being functions, and emphasis on graphical approaches to solving ODEs. The mainstay of the intervention is a set of fifteen guided inquiry tutorials that students experienced in a small-group setting. In this paper we focus on one of these, concerning direction fields. Our research questions are as follows:

(1) Can a fifty-minute guided inquiry tutorial help students understand direction fields? Specifically: 
(a) Can students identify which direction field represents an ODE given in algebraic form?

(b) Can students match a solution curve to the corresponding direction field?

(2) To what extent does our extended guided inquiry intervention change students' conceptual understanding of the solutions to ODEs?

We now turn our attention to the intervention, with a focus on the worksheet on direction fields.

\section{The intervention}

The intervention in its entirety comprises a set of 15 worksheets, mostly accompanied by pre-tests and post-tests, given to students working in a small-group setting. In this section we describe the design of the intervention with a focus on the worksheet on direction fields.

\section{Design restrictions}

The ODE module is taken by physics undergraduates and prospective mathematics teachers in the third year of a four-year degree programme. The intervention was designed to replace weekly 50-minute recitation sessions, in which a problem sheet containing a number of mathematical tasks that allowed students to practice the procedures they saw during lectures was made available online at the beginning of each week. In line with custom and practice, attendance or completion of tutorial work was neither compulsory nor graded.

\section{Underlying theory of learning}

Gresalfi and Lester [21] explain that subscribing to an educational paradigm and allowing it to guide what happens in the classroom is necessary. In this project, a constructivist approach to teaching and learning is adopted, primarily because of the scale and usefulness of relevant research that incorporates it in their conceptual frameworks [22-27]. In particular, the theory has been well developed as it applies to mathematics $[22,28]$.

Constructivism says that students construct their own understanding by actively discussing and grappling with concepts. Social constructivism in particular prioritises 
the role of community in learning. Crotty [29] has highlighted the link that exists between one's worldview, theoretical lens, methodological approach, and methods of data collection, and explains how these elements should be consistent with one another. It follows then that our instructional design must build on constructivism and comprise activities that maximise the opportunity for students to construct their own knowledge and understanding in a classroom environment that supports argumentation and cooperation; see also $[23,30-34]$.

\section{Group work}

By subscribing to a social constructivist theory of learning, we are accepting that group work will play a significant role in student learning. A study of students' attitudes to group work in undergraduate mathematics reported several favourable outcomes [35]. Group work helped students to consolidate and further explore material covered in lectures and retain their concentration levels. Peer discussions facilitated their understanding of the lecture material and made them feel more able to ask for clarification or help from their peers than from the lecturer [35, p.78]. We decided to use groups of no more than four students that are of mixed-ability and gender balanced where possible. This is line with the findings of Gillies [36], who adds that the facilitators need to be trained in how to implement this pedagogical strategy: 'children in structured groups give more detailed and explanatory help to each other, ask deeper and more comprehensive questions, and achieve higher learning outcomes' when these criteria are met; see also [37, 38].

Our reform setting is more guided than that described by Stephan and Rasmussen [7], because our goals are different. We focused on enriching students' concept image of ODEs and were severely constrained by limited contact time, the broad course content, and number of teaching staff per student (1:34).

\section{Activities and questions on worksheets}

The worksheets were designed in a manner similar to that described by Doughty [34]. Our worksheets also include a significant number of mathematical tasks that allow students to develop their instrumental understanding of mathematical concepts relevant to the study of ODEs. 
Each activity comprises several questions. Each activity, as Doughty [34] explains, guides students towards understanding a given concept. Krainer [39] describes this as seeing learners as producers of knowledge, not just consumers. In a guided inquiry approach, each question acts as a stepping stone $[39,40]$ towards understanding the given concept. The optimum 'step size' is that through which the group can navigate using a combination of argumentation and justification. An unnecessarily small 'jump' between questions, and students do not need to interact with each other (which is required to evoke the zone of proximal development (ZPD) [41] and for learning to occur). An oversized gap between questions is one that falls outside the ZPD of the individual with their peers (and even the tutor), and the destination is not reached. An increase in the number of scaffolded questions in a physics setting was requested by students who believed that questions of this nature would help them solve problems in physics [42].

Each activity should end with some form of reflection to allow students to consolidate their learning [40,41] or to highlight any remaining difficulties at the earliest opportunity [40]. In the case of our worksheets, this is achieved through built-in instances where students are asked to discuss their answers with tutors before they progress. These conversations also offer students the opportunity to 'articulate what they know', something that Carpenter and Lehrer deem a necessary provision for students to engage with in order for 'learning with understanding to occur on a widespread basis' [30, p. 24]. Several studies on task design [39, 40, 43-45] were used during the design of the worksheets.

Table 1 provides an overview of all fifteen tutorials. The worksheet on direction fields is the seventh worksheet of fifteen in the intervention.

\section{The Direction Fields tutorial}

Prior to the intervention, direction fields were not part of the course. We decided to include direction fields because they are an excellent way to incorporate graphical representations into the study of first order ODEs and are an important tool for motivating students to think about differential equations visually [46, p.150]. Graphical representations are one of three solution methods (along with numerical and analytical) mentioned by Stephan and Rasmussen [7], and as a form of visualization, are considered by Borrelli and Coleman $[47, \mathrm{p} .1]$ to be vital to understand the dynamical 
aspect of ODEs in an introductory course. The direction field is the only concept that is being added to the curriculum, and the only concept not introduced in lectures.

Unlike Stephan and Rasmussen [7], we do not let students re-create direction fields, but present them as a useful tool. Consequently the first of the six tasks in the worksheet (Appendix A) comprises an introduction, which is unusual in that the students read through our explanation of direction fields in the context of first order ODEs. In the remaining five tasks the students are active participants.

The first two tasks require students to populate an $x, y$-grid with segments of tangents at various points for two ODEs of the form $\frac{d y}{d x}=f(x, y)$. For the first ODE, the slope function $f$ is independent of $x$. For the second, the slope function $f$ depends on both $x$ and $y$, but is undefined when $y=0$. This progression gives students practice constructing fields while also introducing key properties of functions in an attempt to strengthen the link between the function nature of solutions to ODEs and their graphical solution. The third task requires students to work in reverse, as they are asked to select the correct ODE when given a portion of the direction field. In the fourth task students use a Geogebra file to construct a direction field with certain properties, drawing all desired outcomes of the tutorial together in a final activity. The tutorial also contains an extension exercise for groups of students that progress quickly through the worksheet.

\section{Other tutorials focused on solutions to ODEs}

The worksheet on direction fields is one of four whose primary theme is developing conceptual understanding of solutions to an ODE (Table 1).

\section{Table 1}

Worksheet Order, Title, and Primary Theme

\begin{tabular}{lll}
\hline Number & Name & Primary theme \\
\hline $\mathbf{1}$ & Calculus review & Instrumental understanding \\
$\mathbf{2}$ & Meaning of the derivative & The derivative \\
$\mathbf{3}$ & ODEs and their solutions & Solution to ODE \\
$\mathbf{4}$ & Separable equations & Instrumental understanding \\
$\mathbf{5}$ & First order ODEs & Instrumental understanding \\
$\mathbf{6}$ & Practice solving first order ODEs & Instrumental understanding
\end{tabular}


Direction fields

$8 \quad$ Modelling with first order ODEs I

9 Modelling with first order ODEs II

10 Modelling with first order ODEs III

11 Second order ODEs

12 More second order ODEs

13 Solutions to second order ODEs

14 Practice solving second order ODEs

15

Modelling with second order
Solution to ODE

Modelling

Solution to ODE

Modelling

Instrumental understanding

Instrumental understanding

Solution to ODE

Instrumental understanding

Modelling ODEs

We include an activity from each of the other worksheets (Figure 1) as an indication of how students encounter the concept in the other worksheets. All activities highlight that solutions to ODEs are collections of functions, approached from a number of separate, often complementary, directions. Worksheet 3 is primarily about what an ODE is, and what is meant by a solution to an ODE. Worksheet 9 introduces modelling using first order ODEs; the activity shown highlights the graphical representation of the solution to an ODE by giving students an initial condition and asking them to sketch how the solution curve evolves over time. The activity from Worksheet 14 draws together the algebraic and graphical solutions of five second order linear ODEs. Students are asked to match each ODE to its algebraic solution in algebraic and graphical form. 


\section{Activity 3}

1. Given that $y=e^{x}+2 x$, show that:
a. $\frac{d y}{d x}=e^{x}+2$
b. $\frac{\mathrm{d} y}{\mathrm{~d} x}-y=2(1-x)$.

2. Are either of the above differential equations? Justify your answer.

3. What does $y=e^{x}+2 x$ represent in this context?

\section{Discuss your answers with a tutor.}

\section{Definition}

A solution to a differential equation is any function $y(x)$ that satisfies the differential equation in question. That is, when we calculate the derivatives of $y$, and substitute for $y$ and its derivatives, the left hand side is equal to the right hand side for all values of $x$ in the domain of $y$.

Figure 1. Activities from intervention on solution to an ODE. (a) Activity 3 from Worksheet 3

\section{Activity 3}

Sketch the evolution of populations beginning at the initial populations P1, P2, P3, P4 indicated on the graph below. Use the Excel file provided if necessary. The value of $k$ has been drawn already.

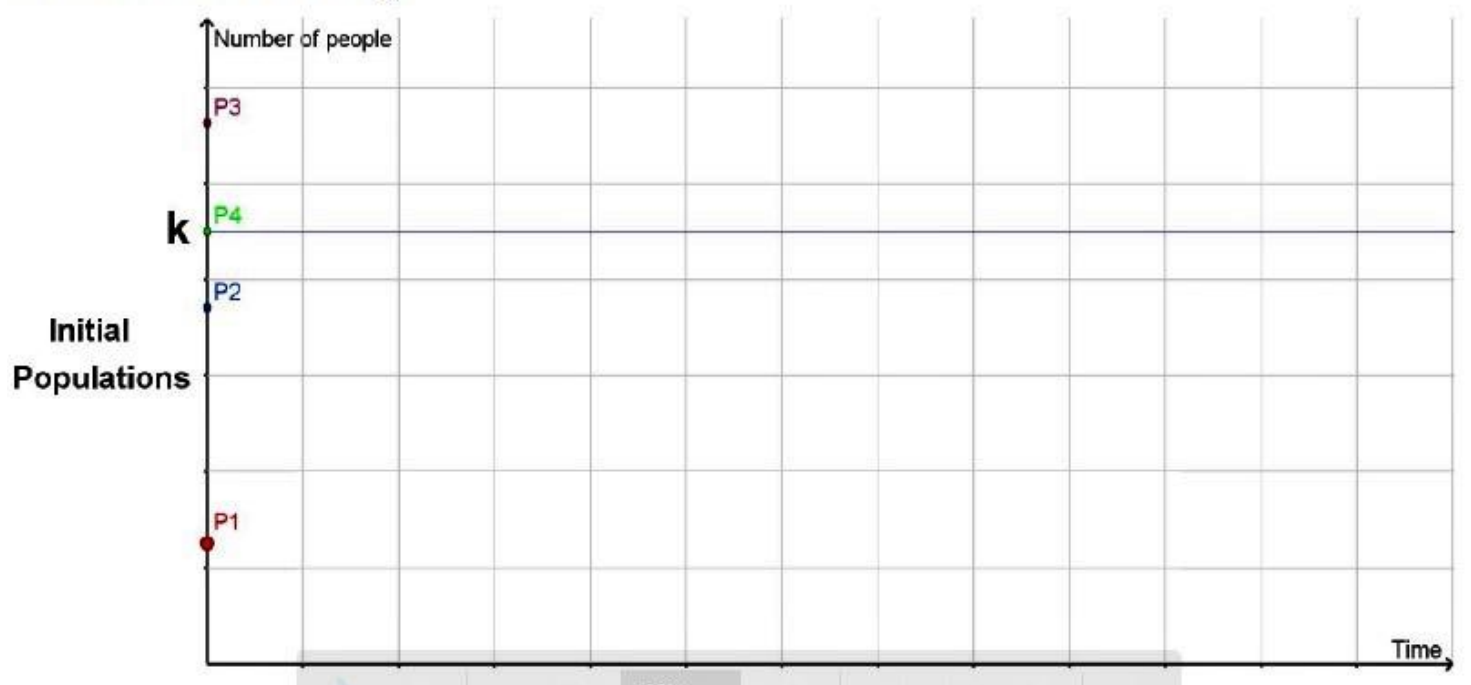

Figure 1. Activities from intervention on solution to an ODE. (b) Activity 3 from Worksheet 9 


\section{Activity 1}

1. Your task is to complete the table by associating the correct solution and graph with each of the following differential equations:

\begin{tabular}{|l|l|l|}
\hline differential equation & solution & graph of solution \\
\hline 1) $y^{\prime \prime}+10 y^{\prime}+9 y=0$ & & \\
\hline$y^{\prime \prime}+4 y^{\prime}+9 y=0$ & & \\
\hline 3) $y^{\prime \prime}+9 y=0$ & & \\
\hline 4) $y^{\prime \prime}-6 y^{\prime}+9 y=0$ & & \\
\hline 5) $y^{\prime \prime}-6 y^{\prime}+9 y=3 x$ & & \\
\hline
\end{tabular}

Figure 1. Activities from intervention on solution to an ODE. (c) Activity 1 from Worksheet 14

\section{Methodology}

A combination of immediate and delayed post-testing and interviews was used to gather the data necessary to answer the research questions. Each post-test contained two questions, one corresponding to RQ1a and one to RQ1b. The immediate post-test provides data on the individual and group level simultaneously with minimal external influences. It was completed by all attendees which resulted in a large response rate that represented every member of the cohort. Data informing RQ1 was also gathered through a written delayed post-test that was given as a question on the terminal exam for the ODE module. This took place eleven weeks after the tutorial. Aligning the questions on both post-tests enabled us to evaluate the long-term impact of the tutorial, albeit influenced by further learning experiences such as Worksheet 14. From a teaching perspective, the delayed post-test question also serves to include more qualitative or conceptual questions in the assessment for the ODE module, as called for by Rowland and Jovanoski [5]. The data presented in this paper is extracted from two successive years' worth of immediate post-test data. Seventy-six students completed the immediate post-test, seventy students completed the delayed post-test.

We used semi-structured interviews to probe students' conceptions of solution to an ODE in more detail. The interviews followed the design guidelines described by Jääskeläinen [48]. Interviews were chosen because of the richness of the data obtained. They can facilitate more open-ended questions than pen and paper tests, and allow for spontaneous lines of enquiry to be followed by the interviewer. We use the data obtained from the interviews to discuss students' understandings of the function nature of solutions to ODEs. This data is used to shape the discussion around RQ2. The 
interviews were conducted on a voluntary basis, six weeks after the tutorial took place. The twelve participants described in this paper represent a broad range of abilities and backgrounds with respect to the student cohort.

\section{Results and discussion}

To answer RQ1, we begin by reporting the students' answers to the immediate post-test questions. Forty-two students completed the immediate post-test (Figure 2) and forty-six students completed the delayed post-test (Figure 3) in Cohort 1. Thirty-four students completed the immediate post-test in Cohort 2.

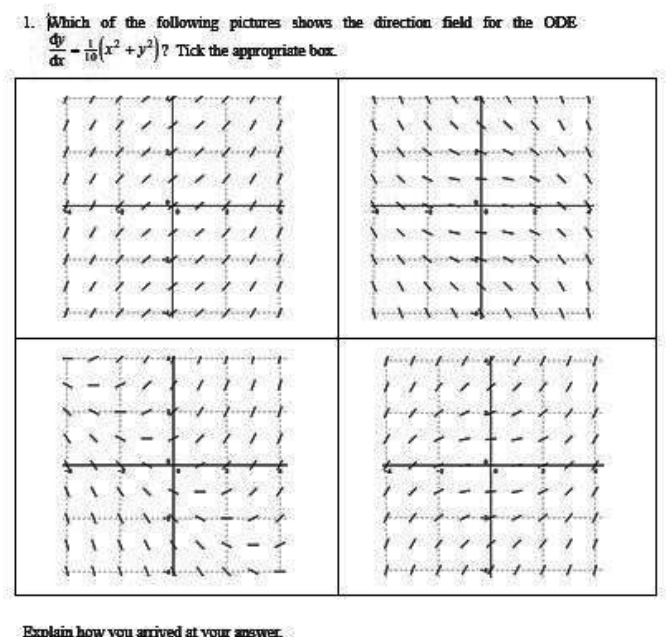

Figure 2. Direction field immediate post-test

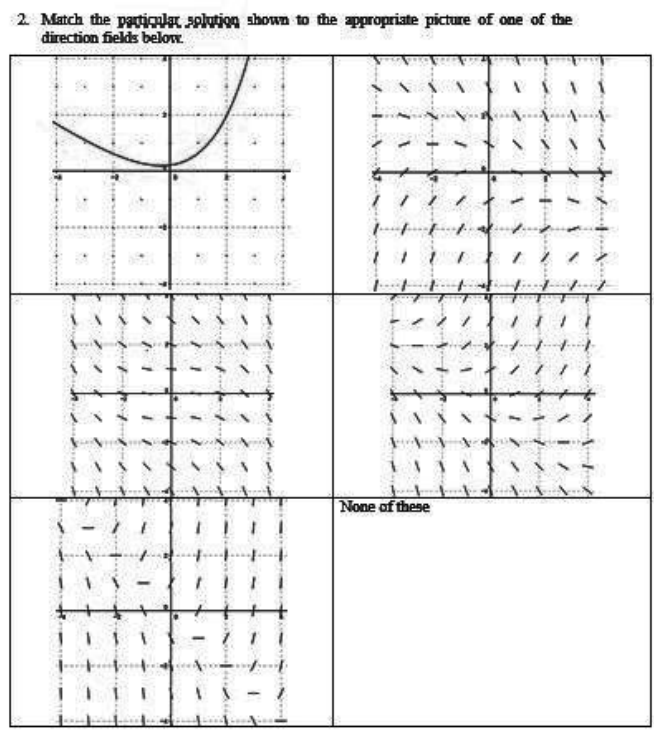

Explain how you antived at your answer. 


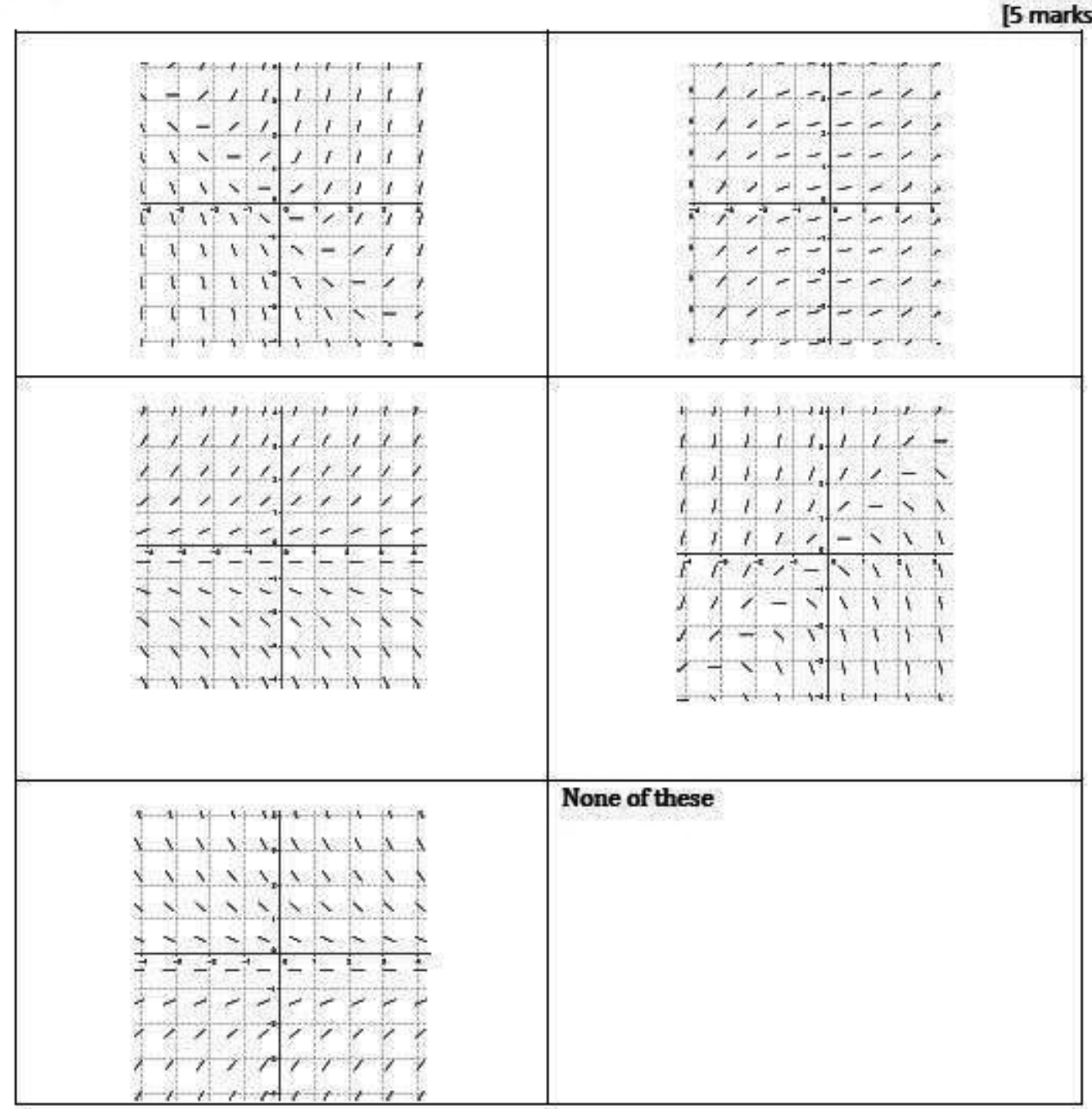

Figure 3. Direction field delayed post-test

\section{Immediate post-test}

RQ1a: Can students identify direction fields when given ODEs in algebraic form?

Question 1 required students to match the $\operatorname{ODE} \frac{d y}{d x}=\frac{1}{10}\left(x^{2}+y^{2}\right)$ to a picture of its direction field and explain how they arrived at their answer. The question was posed to both cohorts as shown in Figure 2, but the nature of one of the incorrect responses was changed. Upon analysing the student responses from Cohort 1, it became apparent that identifying the correct answer was possible by noticing that it was the only solution for which each slope is non-negative. This reasoning was used by the majority of students (55\% of cohort, $66 \%$ of correct answers). We decided to require students to engage in 
further reasoning to identify the correct answer by changing one of the incorrect responses to also have the property that the slope is positive at all points. This meant that students in Cohort 2 could not identify the correct answer by noticing only the sign of the slopes on the direction field..

A total of seventy-six students completed this question across both cohorts, sixty-six of whom $(n=76,87 \%)$ identified the correct direction field. Increasing the difficulty of the problem did not result in a reduction in success, in fact the success rate increased from $83 \%(n=42)$ in Cohort 1 to $91 \%(n=34)$ in Cohort 2. A breakdown of the responses is outlined in the following table.

Table 2

Responses to Immediate Post-Test Q1

\begin{tabular}{|c|c|c|c|}
\hline response & $\begin{array}{l}\text { Cohort } 1 \\
(\mathrm{~N}=42)\end{array}$ & $\begin{array}{l}\text { Cohort } 2 \\
(\mathrm{~N}=34)\end{array}$ & all $(\mathrm{N}=76)$ \\
\hline correct direction field chosen & $83 \%(35)$ & $91 \%(31)$ & $87 \%(66)$ \\
\hline incorrect field & $14 \%(6)$ & $9 \%(3)$ & $12 \%(9)$ \\
\hline Correct but incomplete reasoning & $14 \%(6)$ & $3 \%(1)$ & $9 \%(7)$ \\
\hline Combination of correct and incorrect reasoning & $0 \%(0)$ & $3 \%(1)$ & $3 \%(1)$ \\
\hline No explanation & $0 \%(0)$ & $3 \%(1)$ & $3 \%(1)$ \\
\hline no answer & $2 \%(1)$ & $0 \%(0)$ & $1 \%(1)$ \\
\hline total & $100 \%(42)$ & $100 \%(34)$ & $100 \%(76)$ \\
\hline \multicolumn{4}{|c|}{ Reasoning Given for Choosing the Correct Direction Field } \\
\hline \multirow[t]{2}{*}{ Explanation } & Frequency & & \\
\hline & $\begin{array}{l}\text { Cohort } 1 \\
(N=35)\end{array}$ & $\begin{array}{l}\text { Cohort } 2 \\
(N=28)\end{array}$ & $\begin{array}{l}\text { Both } \\
\text { Cohorts } \\
(N=63)\end{array}$ \\
\hline The slope at all points must be positive & $66 \%(23)$ & $36 \%(10)$ & $52 \%(33)$ \\
\hline $\begin{array}{l}\text { Tested various points to see if slope matched the } \\
\text { diagram }\end{array}$ & $26 \%(9)$ & $32 \%(9)$ & $29 \%(18)$ \\
\hline Blank & $3 \%(1)$ & $32 \%(9)$ & $16 \%(10)$ \\
\hline Other (mentioned by one student) & $6 \%(2)$ & $0 \%(0)$ & $3 \%(2)$ \\
\hline
\end{tabular}

Given the change of options presented to students in this question we discuss the reasoning used by each cohort separately.

$\underline{(\text { Cohort } 1, \mathrm{n}=42)}$

Forty-two students completed the immediate post-test in Cohort 1. Thirty-five students (83\%) identified the correct answer to Question 1, with the remaining seven students $(17 \%)$ choosing an incorrect direction field $(n=6)$ or leaving the question blank $(n=1)$. 
The frequencies of explanations given by students who answered correctly is recorded in Table 2.

One common strategy $(26 \% ; n=9)$ was to substitute coordinate values into the ODE to calculate the slope of the solution curve at the corresponding points, and to compare the results with the options provided for the direction field. A second common strategy $(66 \% ; n=23)$ was to compare the sign of the slope (which is positive except at the origin where it is zero) with the slopes indicated by the direction fields. It is noteworthy that all six of the students who gave an incorrect solution used similar reasoning. The salient difference was that they either did not use this information (slope value, slope sign) to select the correct answer, or (in the case of those who tested points) did not exhaust this method to rule out all other options. An example of incorrectly using information is a student who reasoned that the slope will be positive at every point choosing an option where negative slopes are present. An example of a student who tested points in a nonexhaustive manner is discussed below (Figure 4).

\section{$\underline{(\text { Cohort 2, } \mathrm{n}=34)}$}

Thirty-one students (91\%) chose the correct direction field. Seven of these students $(21 \%)$ tested various points to see if the slope matched the diagram, which is unchanged from the previous cohort. Twenty-one students (62\%) used slope comparison reasoning when selecting their answer which is a slight increase from the prior year. Sixteen of these students (47\%) supplemented this information by evaluating the slope at the origin, and comparing their value with the slope at the origin on the potentially correct direction fields. Every student who reasoned this way identified the correct direction field. The remaining five students $(15 \%)$ also selected the correct option, though no further reasoning was indicated in their response. Seven students $(21 \%)$ tested various points to see if the slopes matched the diagram, which is a slight reduction from the previous year.

Three students answered Question 1 unsuccessfully. As in Cohort 1, two of these students displayed some elements of correct reasoning (the other gave no explanation). One used a combination of correct and incorrect reasoning, and the final student used correct, but incomplete reasoning to arrive at their answer. An example is shown (Figure 4) where the student correctly evaluated the slope at a variety of points but arrived at the incorrect answer because their method was not exhaustive. 


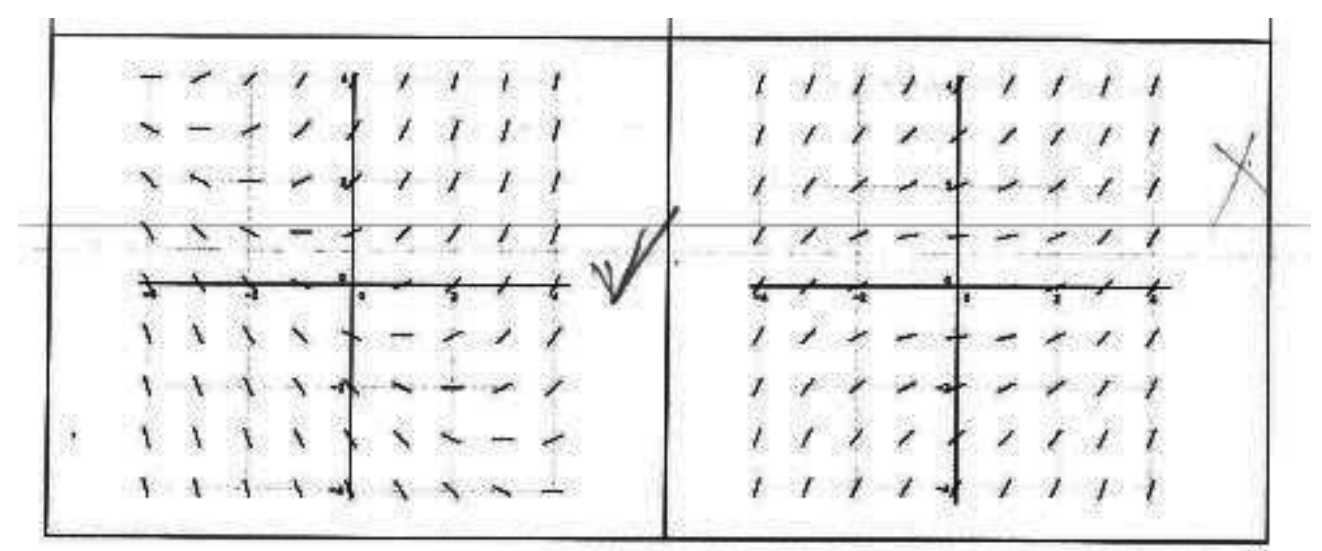

Explain how you arrived at your answer.

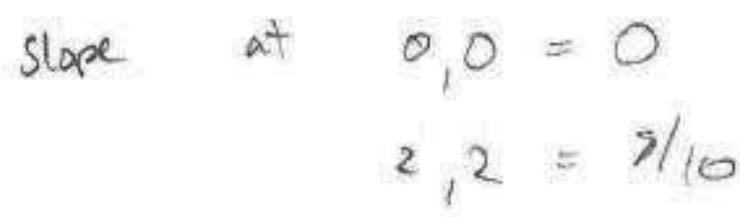

Figure 4. Incomplete 'evaluating points' approach

Across both cohorts, sixty-six students (87\%) correctly identified the direction field of a given ODE. Furthermore, eight of the nine students who chose incorrectly used correct reasoning techniques but did not apply them extensively enough to rule out all of the incorrect options. We conclude that the tutorial is effective at instructing students on reading direction fields.

$R Q 1 b:$ Can students match a solution curve to the appropriate direction field?

Question 2 on the immediate post-test required students to match the solution curve of an ODE to the correct direction field (Figure 2). The students were given five options.

\section{$\underline{(\text { Cohort } 1, \mathrm{n}=42)}$}

Thirty-nine of the students (93\%) answered Q2 correctly. The most popular explanation (given by twenty-five students) was that the direction field chosen offered the 'best fit' for the solution curve. These students took a visual approach, superimposing the curve onto each potential direction field before picking the one where the line segments on the field acted as tangents to the solution curve. An exemplar for this technique is shown in Figure 5. The second most popular justification (given by four students) was to pick points that the curve passed through, calculate the slope of the tangent at these points and investigate them on each field, and choose the closest match. Two students 
described the direction fields qualitatively and then examined the solution curve to see if they were consistent.

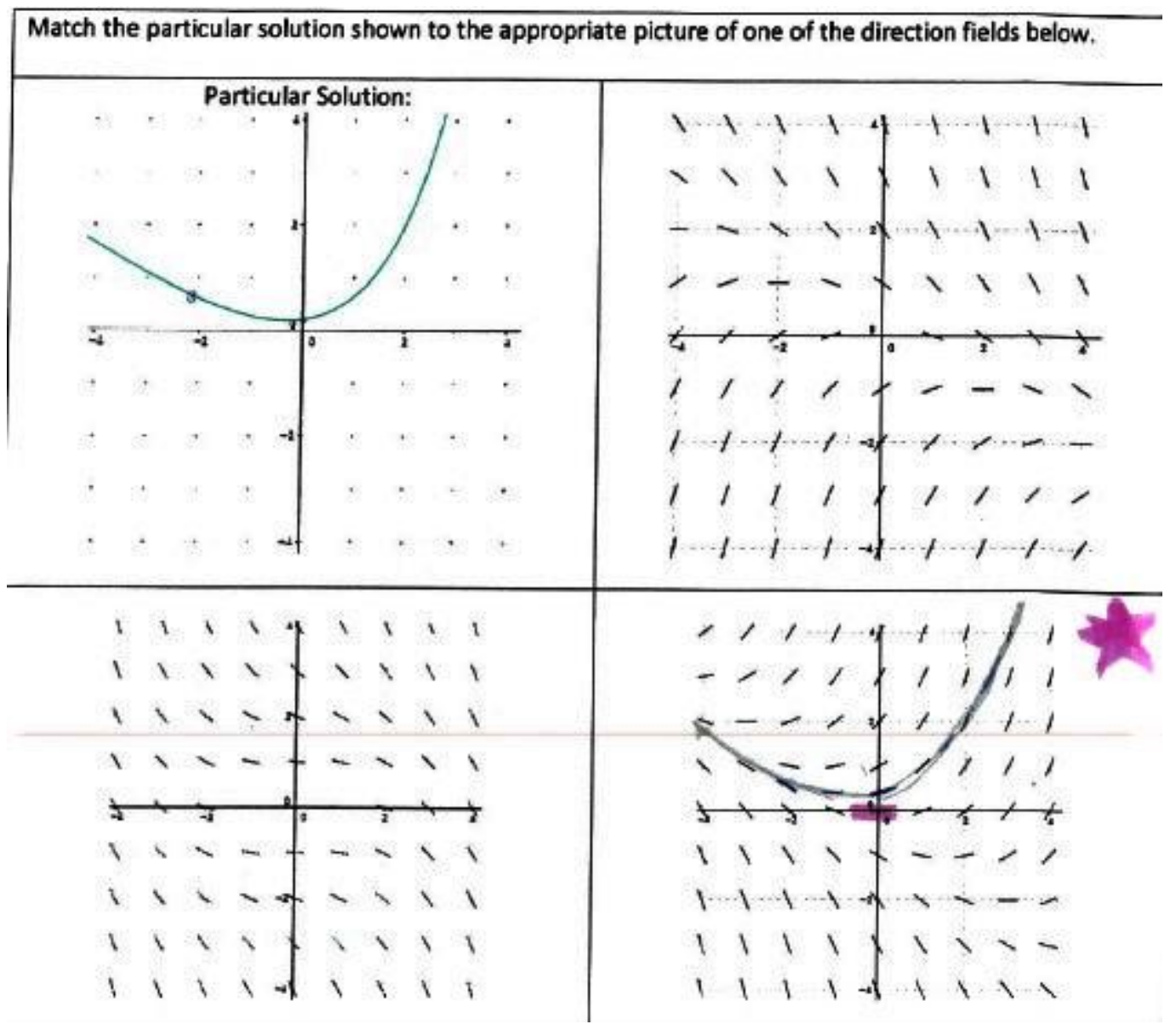

Figure 5. Superimposing the curves' approach

Of the three students who did not choose correctly, one used a visual approach but executed the strategy incorrectly to pick an incorrect graph. The remaining two chose "none of the above". In one case the student said that the answer will be similar to the correct answer but will not have $\frac{d y}{d x}=0$ at $(0,0)$, which, to them, ruled out the correct answer.

\section{$\underline{(\text { Cohort 2, } \mathrm{n}=34)}$}

The reasoning employed by students in Cohort 2 to select the correct answer are included in Table 2.

An interesting answer (Figure 6) appears to have used a combination of the two most popular techniques in a unique way. It appears that the student drew tangent lines to the solution curve at various points and also extended the tangent lines at the same 
point on the direction field to highlight the solution curve to arrive at their answer. This unique combination is indicative of a student who could reason with this task in both an analytical and graphical manner.

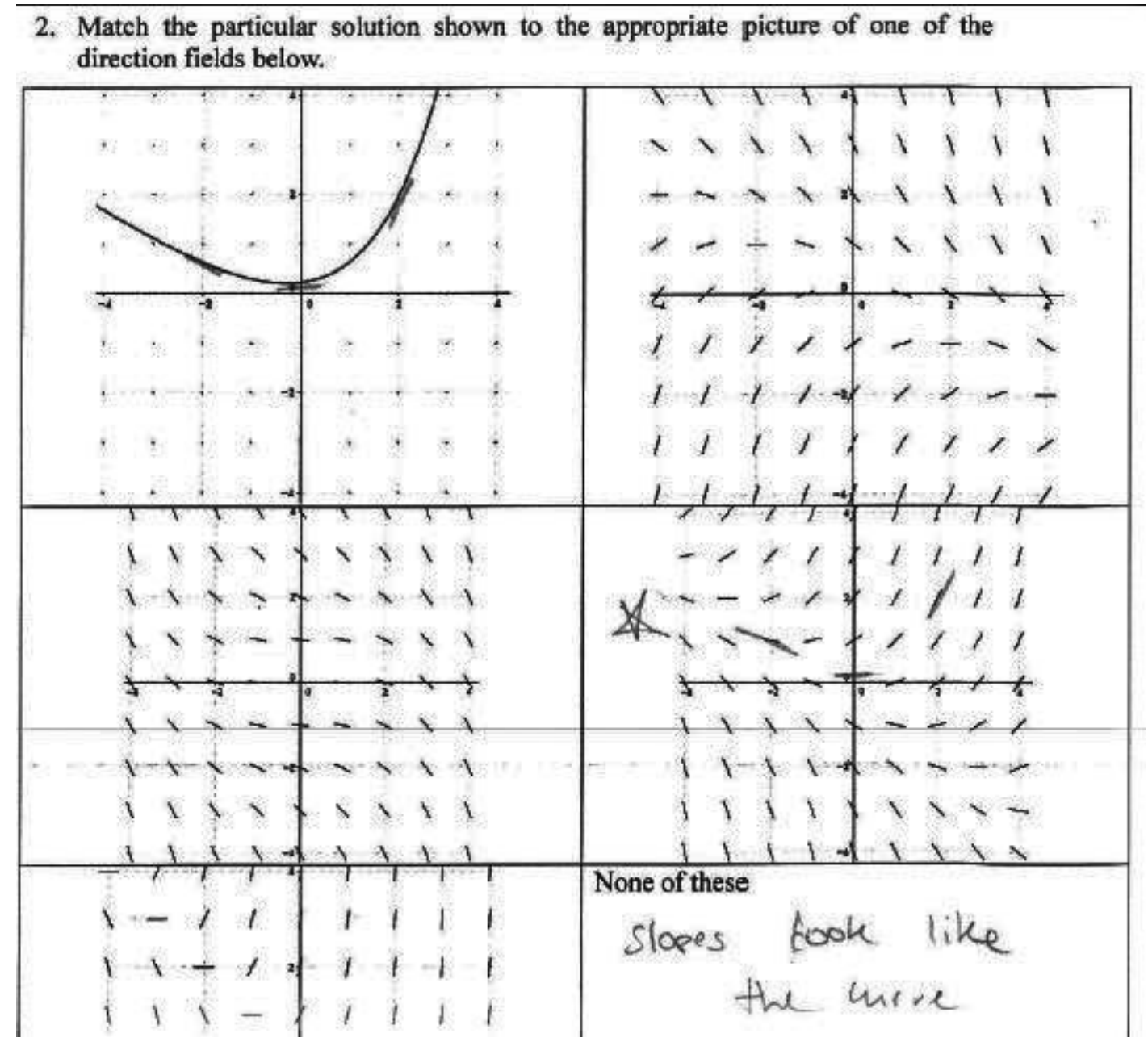

Figure 6. Answer containing a combination of two approaches

Four incorrect answers were given to this question. Three of these four students gave an explanation. One student chose "none of these" but reasoned correctly by attempting to join slope lines. They were unsuccessful because the lines they drew didn't match the solution curve. One student's qualitative approach resulted in them selecting the direction field on the bottom left of the page, writing that "negative slope for negative $x$ values, positive slope for positive $x$-values". The final student left the question unanswered.

We conclude that the tutorial is effective at instructing students on the relationship between solution curves and direction fields. Across both cohorts, sixtyseven students $(88 \%)$ correctly matched a solution curve to its direction field. Similar to the previous question, a large portion of the incorrect solutions carried correct 
reasoning. All of the students who chose incorrectly used reasoning that when applied correctly, would yield the correct answer.

\section{Delayed post-test}

\section{$\underline{\text { (Cohort } 1 \text { only, } \mathrm{n}=46)}$}

To evaluate the long-term effectiveness of the direction field worksheet, a delayed posttest was administered as part of the final exam for the ODE module eleven weeks after the tutorial was completed. The delayed post-test contained an isomorphic equivalent to Question 1, and a question similar to Question 2 asking students to draw the solution curve themselves having provided them with a point through which their curve must pass. Extending the task from the immediate pre-test in this manner allowed use to assess additional elements of students' understanding of direction fields.

Can students identify direction fields when given an ODE in algebraic form?

Of the forty-six students who completed the delayed post-test, thirty-nine students $(85 \%)$ identified the correct direction field. This reflects strongly on the effectiveness of the tutorial over time when compared to the immediate post-test success rate of $87 \%$ : the interval between the tutorial and delayed post-test was eleven weeks and students had not worked with direction fields during this time.

Can students match a solution curve to the appropriate direction field?

Fifteen students (33\%) successfully answered the second question on the delayed posttest which required them to draw the solution of the ODE that passed through the point $(1,1)$ on the direction field they chose in Question 1. A further nine students (20\%) drew a correct solution curve but only propagated to the right $(x \geq 1)$. The nature of the incorrect answers is outlined in Table 3.

Table 3

Category of Incorrect Responses to Delayed Post-Test Question

\begin{tabular}{ll}
\hline Description of attempt & Number of students \\
\hline Drew a small segment of the correct tangent line at the point & 6 \\
$(1,1)$ & \\
Didn't submit the answer sheet with their exam & 4
\end{tabular}


Drew inaccurate curves through $(1,1) \quad 3$

Other 3

Drew multiple curves on the DF, one of which was the correct 2 solution curve through $(1,1)$

Drew a tangent line through $(1,1) \quad 2$

Blank 1

Total 21

While it is clear that the students were less successful with the second delayed post-test question, we believe this is due at least in part to the difference in task between the immediate and delayed post-test. Specifically, we believe that drawing in a solution curve is more difficult than deciding which direction field a curve belongs to. We also note that 18 of the 21 incorrect responses described in Table 3 do not correspond to functions. In this way, the delayed post-test question highlights an area where the tutorial may be improved.

\section{Interview data on solutions to ODEs}

Semi-structured interviews were conducted to learn more about what students understand about solutions to ODEs. As stated above, helping students understand that functions are solutions to ODEs is one of our goals, pursued in four of the tutorials. We cannot ascribe any change to any single tutorial.

Individual interviews were conducted with students lasting approximately twenty minutes. The students self-selected for interviews. The achievements of these students were representative of the range of abilities of the entire cohort. Questions varied across interviews, but students' conceptions of solutions to ODEs were explored with twelve of the participants. We focused on two notions: solutions to ODEs are functions (of the correctly identified independent and dependent variables), and solutions can be verified by substituting them into the ODE (and obtaining an identity).

All of the data gathered during interviews was analysed as described by Thomas [49], who details a general inductive approach to qualitative data analysis.

RQ2: To what extent can an extended guided inquiry intervention change students' conceptual understanding of the solutions to ODEs?

The data discussed in this section was obtained in response to a variety of questions. We asked students what they knew about solutions to ODEs and what is 
meant by a solution of an ODE. We also asked students about how they might know whether a given function was a solution to an ODE, though we only asked students who knew that a solution is a function. The ODE used during interviews $\left(\frac{d y}{d x}=\frac{(0.5+y)}{2}\right)$ was the same ODE used for the delayed post-test. Table 4 shows the success rate of students in response to both of these properties of solutions to ODEs.

Table 4: Student responses to questions on solutions of ODEs.

\begin{tabular}{lllll}
\hline Category & $\begin{array}{l}\text { Solution is a } \\
\text { function }\end{array}$ & $\begin{array}{l}\text { Function of } \\
\text { correct } \\
\text { variables }\end{array}$ & $\begin{array}{l}\text { Substitute in to } \\
\text { ODE to verify }\end{array}$ & 0=0 iff solution \\
\hline Correct & 11 & 12 & 10 & 9 \\
Incorrect & 1 & 0 & 1 & 2 \\
\hline
\end{tabular}

Eleven of the twelve students knew that the solution would be a function, and that the function would have the form $y=f(x)$ (or equivalently, $y(x)$ ). The twelfth student stated that ' $y(x)=$ something', indicating that they understood the importance of the variables in the derivative without stating explicitly that $y(x)$ is a function.

We wanted students to explain that the solution to the ODE is verified by substituting the solution function into the ODE, and to do this. Ten of the eleven students were able to explain this, but one of these was unsure how to show this. They understood that if they differentiated their solution they would get $\frac{d y}{d x}=\frac{(0.5+y)}{2}$, but didn't recognise the $y(x)$ on the RHS of the ODE as the solution. Thus, this student failed to appreciate what we will call the dual role of $y(x)$ in verifying a solution: it is both the function whose derivative appears in the equation, and the function which appears in the equation in un-differentiated form. The final student, who didn't know how to verify the solution, was the 'twelfth student' referred to above.

\section{Summary}

A question contained in the previous study [1] asked students to write down everything they knew about the solutions to differential equations. Although it is an open-ended question, the fact that only one student out of eighteen (6\%) mentioned that solutions are functions is in stark contrast to the post-intervention results, where eleven of the twelve students $(92 \%)$ that were interviewed on completion of the entire module stated 
this. Further, all twelve students understood the variables of the function. A similar majority of students $(90 \%, n=11)$ interviewed demonstrated an understanding of what is meant by a solution to an equation, with all except one of these students understanding the dual role of $y(x)$ in verifying the solution. We interpret this as an addition to the concept image of students resulting from the intervention.

\section{Conclusions}

Much of the literature on direction fields (and other graphical representations) recommends their inclusion in courses and assessments [7, 9, 50]. We introduced direction fields in a service course on ODEs, resulting in significant gains in the concept image of the students. The immediate post-test showed that students were able to identify direction fields when given the ODE in analytical form (88\%) and to match a solution curve to the appropriate direction field (93\%) with great success. The delayed post-test also showed that the instruction had a long-lasting impact, with the success of students' ability to identify direction fields when given the ODE in analytical form remaining similar (85\%). Interview data revealed improved understanding of the concept of a solution to an ODE as a result of the intervention. Specifically, the data showed that notions of 'solution as a function' and 'verification of a solution' are now known by most students in some contexts.

However, in other contexts there appears to be a discontinuity between students' responses to the delayed post-test question and their understanding of the function nature of solutions to ODEs. We reported in the previous section that eighteen of the thirty incorrect responses to Question 2 on the delayed post-test do not correspond to functions, as they failed the vertical line test. We think it is likely that insufficient understanding of the concept of a function here impedes a good understanding of the concept "solution is a function". This warrants further investigation.

\section{Implications for teaching}

While the worksheet presented in this paper is part of a larger intervention, it can be implemented as a once-off interaction with students in courses where adopting the entire intervention is unfeasible. we suggest that courses that do not cover direction fields as part of their course can use the worksheet in isolation given its success with our students. 
We plan to make two changes to this tutorial: (i) the link between graphical and analytical solution techniques needs to be a focus of conversation (particularly during introductory portion of the worksheet) and (ii) emphasizing the function nature of solutions to ODEs and how that links to a solution curve on an ODE. We encourage potential users to adapt the worksheet to suit their learners and welcome any feedback and experiences they have. 


\section{Reference list}

1. D. Hyland, P. van Kampen and B.C. Nolan. Outcomes of a service teaching module on ODEs for physics students. International journal of mathematics education in science and technology, 2017, 49 (5), p.743-758.

2. M. Artigue, C. Batanero and P. Kent. Mathematical thinking and learning at postsecondary level. In: F.K. Lester Jr (ed.), Second handbook of research on mathematics teaching and learning vol. 2. Information age publishing, 2007, p.1011-1049.

3. S. Habre. Investigating students' approval of a geometrical approach to differential equations and their solutions. International journal of mathematics education in science and technology, 2003, 34 (5), p.651-662.

4. S. Habre. Exploring Students' Strategies to Solve Ordinary Differential Equations in a Reformed Setting. Journal of mathematical behaviour, 2000, 18 (4), p.455-472.

5. D.R. Rowland and Z. Jovanoski. Student interpretations of the terms in first-order ordinary differential equations in modelling contexts. International journal of mathematics education in science and technology, 2004, 35 (4), p.503-516.

6. P. Davis. Asking Good Questions About Differential Equations. The college mathematics journal, 1994, 25 (5), p. 394-400.

7. M. Stephan and C.L. Rasmussen. Classroom mathematical practices in differential equations. Journal of mathematical behaviour, 2002, 21, p.459-490.

8. S. Ainsworth. The functions of multiple representations. Computers and education, 1999, 33, p.131-152.

9. S. Ainsworth. The educational value of multiple-representations when learning complex scientific concepts. In: J.K. Gilbert et al., (eds), Visualization: theory and practice in science education, Springer. 2008, p.191-208.

10. M. Yerushalmy and J.L. Schwartz. A procedural approach to exploration in calculus. International journal of mathematics education in science and technology, 1999, 30 (6), p.903-914.

11. M. Camacho-Machín, J. Perdomo-Diaz and M. Santos-Triago. An exploration of students' conceptual knowledge built in a first ordinary differential equations course (part I). The teaching of mathematics, 2012, Vol XV (1), p.1-20.

12. D. Raychaudhuri. Dynamics of a definition: a framework to analyse student construction of the concept of solution to a differential equation. International journal of mathematics education in science and technology, 2009, 39 (2), p.161-177.

13. C.L. Rasmussen. New directions in differential equations: A framework for interpreting 
students' understandings and difficulties. Journal of mathematical behavior, 2001, 20, p.55-87.

14. M. Zandieh and M. McDonald. Student understanding of equilibrium solutions in differential equations. In: F. Hitt \& M. Santos (eds), Proceedings of the 21st Annual Meeting of the North American Chapter of the International Group for the Psychology of Mathematics Education, Columbus, OH: ERIC. 1999, p.253-258.

15. K.A. Keene, M. Glass and J.H. Kim. Identifying and Assessing Relational Understanding in Ordinary Differential Equations. In Proceedings 2011 frontiers in education (FIE 20110). Rapid City, SD. October, 2011, p. S4B-1.

16. D.G. Mallet and S.W. McCue. Constructive development of the solutions of linear equations in introductory ordinary differential equations. International journal of mathematics education in science and technology, 2009, 40 (5) p.587-595.

17. K. Afasamaga-Fuata. An undergraduate student's understanding of differential equations through concept maps and vee diagrams. In Proceedings of the First International Conference on Concept Mapping. Pamplona, Spain, 2004.

18. M.K. Ju and O.N. Kwon. Ways of talking and ways of positioning: students' beliefs in an inquiry-oriented differential equations class. Journal of mathematical behavior, 2007, 26, p.267-280.

19. S. Waddy, J.H. Kim and M. Glass. Tutoring dialogue goals for conceptual understanding of differential equations: preliminary work. In Proceedings of the 20th Midwest AI and Cognitive Science Conference. Indiana Purdue Fort Wayne, 2009.

20. C.L. Rasmussen and K.D. King. Locating starting points in differential equations: a realistic mathematics education approach. International journal of mathematical education in science and technology, 2000, 31 (2), p.161-172, DOI: $\underline{10.1080 / 002073900287219}$

21. M.S. Gresalfi and F. Lester. What's worth knowing in mathematics? Constructivist instruction, 2009, p.276-302.

22. I. Arnon, J. Cottrill, E. Dubinksy, A. Oktac, S. Roa Fuentes, M. Trigueros, and K. Weller. APOS Theory: A framework for research and curriculum development in mathematics education. New York: Springer. 2013.

23. P.S. Shaffer and L.C. McDermott. Research as a guide for curriculum development: An example from introductory electricity. part ii: Design of instructional strategies. American journal of physics, 1992, 60 (11), p.994-1003.

24. L. Doughty, E. McLoughlin, P. van Kampen. What integration cues, and what cues integration in intermediate electromagnetism. American journal of physics, 2014, 82 (11), p.1093-1103. 
25. C.L. Rasmussen, K. Marrongelle, O.N. Kwon, and A. Hodge. Four goals for instructors using inquiry-based learning. Notices of the American Mathematical Society, 2017, 64 (11).

26. N. Challis. 2015. Group work within undergraduate mathematics In: M. Grove, T. Croft, J. Kyle and D. Lawson (eds). Transitions in undergraduate mathematics education. Birmingham: The University of Birmingham, p.85-96.

27. M. Van Den Heuvel-Panhuizen. The didactical use of models in realistic mathematics education: An example from a longitudinal trajectory on percentage. Educational Studies in Mathematics, 2003, 54 (1), p.9-35.

28. D.O. Tall. The three worlds of mathematics. For the Learning of Mathematics, 2004, 23 (3), p.29-33.

29. M. Crotty. The foundations of social research: Meaning and perspective in the research process. Sage, 1998.

30. T.P. Carpenter, and R. Lehrer. Teaching and learning mathematics with understanding. Mathematics classrooms that promote understanding, 1999, p.19-32.

31. L.C. McDermott. Guest comment: How we teach and how students learn a mismatch? American journal of physics, 1993, 61, p.295-298.

32. E.F. Redish. Implications of cognitive studies for teaching physics. American journal of physics, 1994, 62 (9), p.796-803.

33. D. Hestenes. Who needs physics education research!? American journal of physics, 1998, 66, p.465-467.

34. L. Doughty. 2013. Designing, implementing and assessing guided-inquiry based tutorials in introductory physics. $\mathrm{PhD}$ thesis. Dublin City University.

35. L. Walker. Enabling students to become independent learners In: M. Grove, T. Croft, J. Kyle and D. Lawson (eds). Transitions in undergraduate mathematics education. Birmingham: The University of Birmingham, 2015, p.71-84.

36. R.M. Gillies. Structuring cooperative group work in classrooms. International journal of educational research, 2003, 39, p.35-49.

37. R.A. Lotan. Complex instruction: An overview. In: E.G. Cohen and R.A. Lotan (eds), Working for equity in heterogeneous classrooms. New York: Teachers College Press. 1997, p. 15-27.

38. E.G. Cohen, R.A. Lotan and N.C. Holthuis. Organising the classroom for learning. In: E.G. Cohen and R.A. Lotan (eds), Working for equity in heterogeneous classrooms. New York: Teachers College Press. 1997, p.31-43.

39. K. Krainer. Powerful tasks: A contribution to a high level of acting and reflecting in mathematics instruction. Educational studies in mathematics, 1993, 24, p. 65-93. 
40. A. Bell. Principles for the design of teaching. Educational studies in mathematics, 1993, 24 (1), p.5-34.

41. L. Vygotsky. Mind in society: the development of higher mental process. Cambridge (MA): Harvard University Press, 1978.

42. L. Cui, N.S. Rebello, P.R. Fletcher, and A.G. Bennett. Transfer of learning from college calculus to physics courses. In: Proceedings of the NARST 2006 National Meeting. San Francisco, California. 2006. [Online]. Available from: https://www.researchgate.net/profile/N Sanjay Rebello/publication/242297311 TRAN SFER_OF_LEARNING_FROM_COLLEGE_CALCULUS_TO_PHYSICS_COURSE S/links/0c960532638f5bfd86000000.pdf [Accessed 1 June 2017]

43. A. Pointon and C. Sangwin. An analysis of undergraduate core material in the light of hand-held computer algebra systems. International journal of mathematics education in science and technology, 2003, 34 (5), p.671-686.

44. C. Sangwin. New opportunities for encouraging higher level mathematical learning by creative use of emerging computer assessment. International journal of mathematics education in science and technology, 2003, 34 (6), p.813-829.

45. N. Curley and M. Meehan. Example generation exercises in an introductory analysis course. MSOR Connections, 2010, 10 (1), p.48-51.

46. H. Gollwitzer. Visualisation in differential equations. In: W. Zimmermann and S. Cunningham (eds), Visualization in teaching and learning mathematics. Washington, DC: Mathematical Association of America, 1991, p.149-155.

47. R.L. Borrelli and C.S. Coleman. Differential equations, a modelling perspective. New York: John Wiley and Sons. 1998.

48. R. Jääskeläinen. Think-aloud protocol. In: Y. Gambier and L. van Doorslaer (eds). Handbook of translation studies volume 1. Amsterdam: John Benjamins publishing company. 2010, p.371-374.

49. D.R. Thomas. A general inductive approach for analyzing qualitative evaluation data. American Journal of Evaluation, 2006, 27, p.20-26.

50. M. Swan. The impact of task-based professional development on teachers' practices and beliefs: A design research study. Journal of mathematics teacher education, 2007, 10 (4-6), p.217-37. 
Appendix A 


\section{Introduction}

This tutorial focuses on direction fields and graphing solutions to differential equations. A direction field (also called slope field) is a graphical representation of the solutions of a first order ODE. It is useful because it can be created without solving the ODE analytically.

\section{Constructing a direction field}

Consider the first order ODE $\frac{d y}{d x}=x$, and imagine that you do not know how to solve it.

To get a feel for the behaviour of the solution, you may evaluate $\frac{d y}{d x}$ at a variety of points $(x, y)$ and use each value as the slope of the tangent to the solution curve at $(x, y)$.

Starting with a blank pair of axes, you may populate the graph by evaluating the slope at different points, and plotting the slopes as short line segments centred on each point.

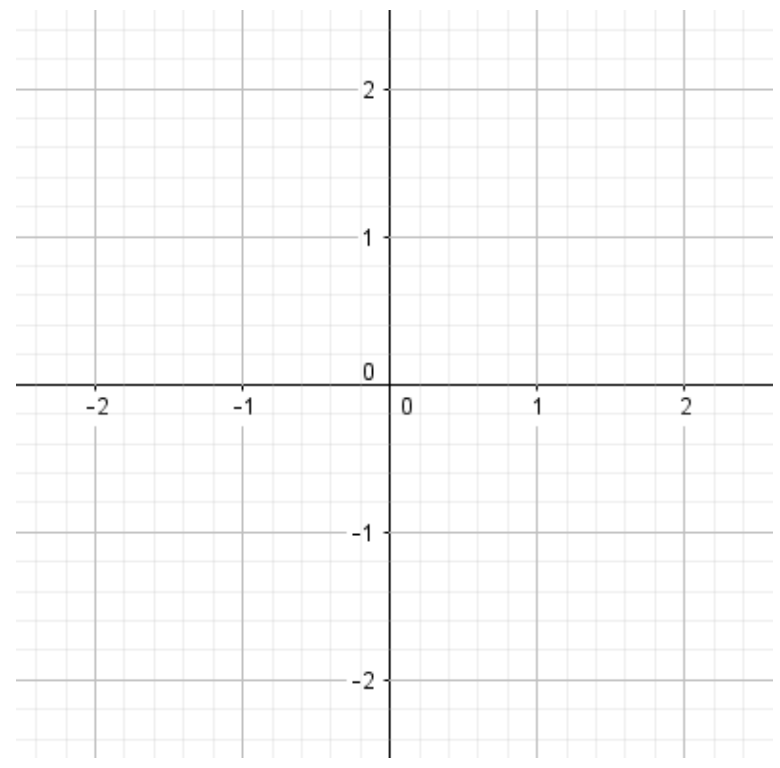

For example, let's evaluate $\frac{d y}{d x}$ at point $(0,0)$. At this point $\left.\frac{d y}{d x}\right|_{x=0}=\left.x\right|_{x=0}=0$, so we draw a line segment with slope 0 at the point $(0,0)$. At the point $(1,1),\left.\frac{d y}{d x}\right|_{x=1}=$ $\left.x\right|_{x=1}=1$, so draw a line segment with slope 1 at the point $(1,1)$. When you evaluate 
each of the points and draw in the line segments of appropriate slope you begin to see a picture of the behaviour of the solutions. 


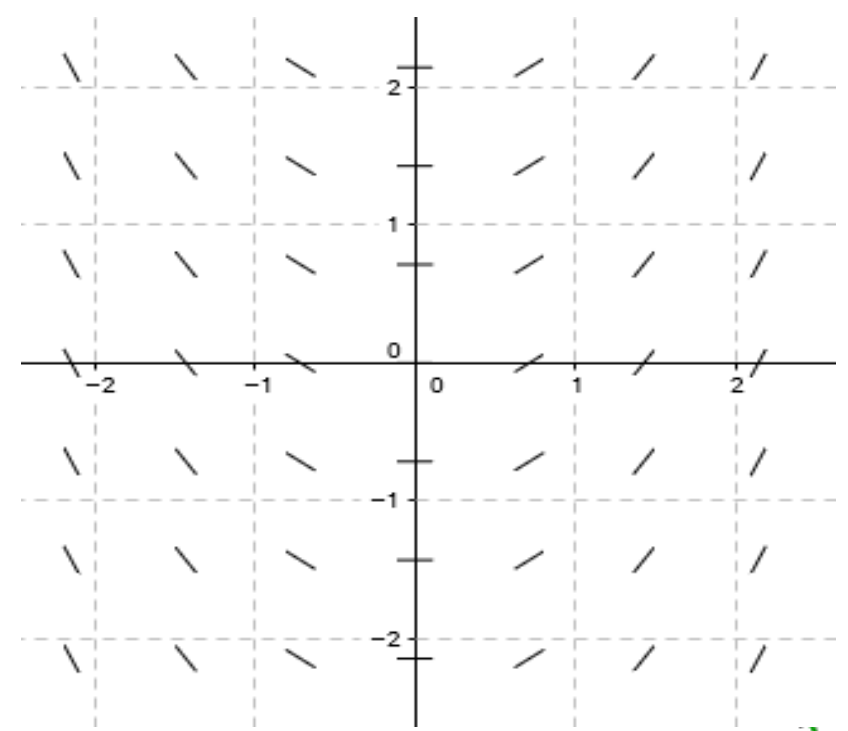

A large number of such line segments are shown at left. If you draw curves tangent to these segments, each curve satisfies the relation between the derivative and the function given by the ODE. Each curve therefore represents a particular solution to the ODE, and all curves together represent a family of functions that are the general solution to the ODE.

As an example, starting at the point $(0,0)$ you can work forwards and backwards to construct the graph of the solution to the differential equation $\frac{d y}{d x}=x$ that passes through the point $(0,0)$, as shown at right.

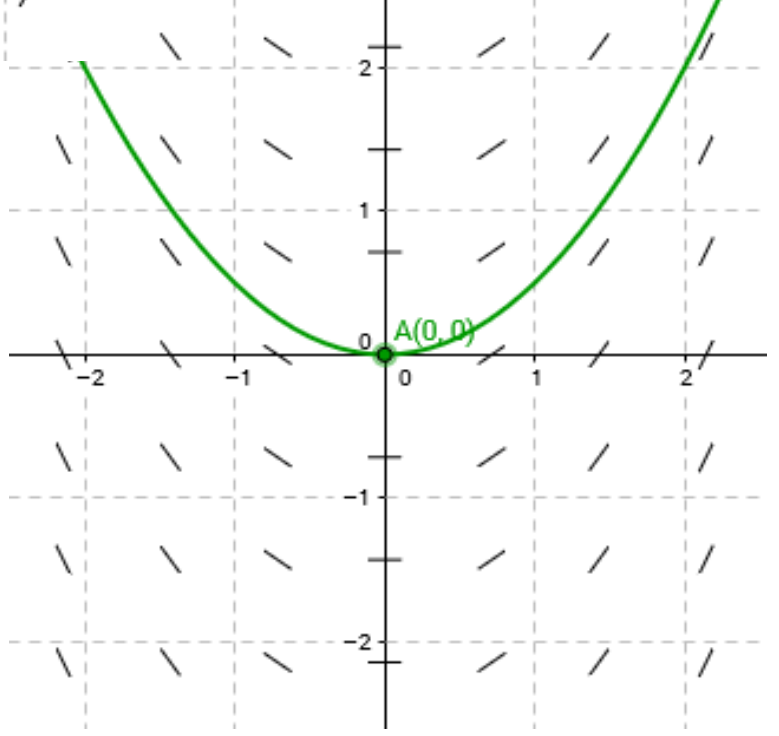

Four particular solutions to the first order differential equation $\frac{d y}{d x}=x$ are shown in the direction field below. 


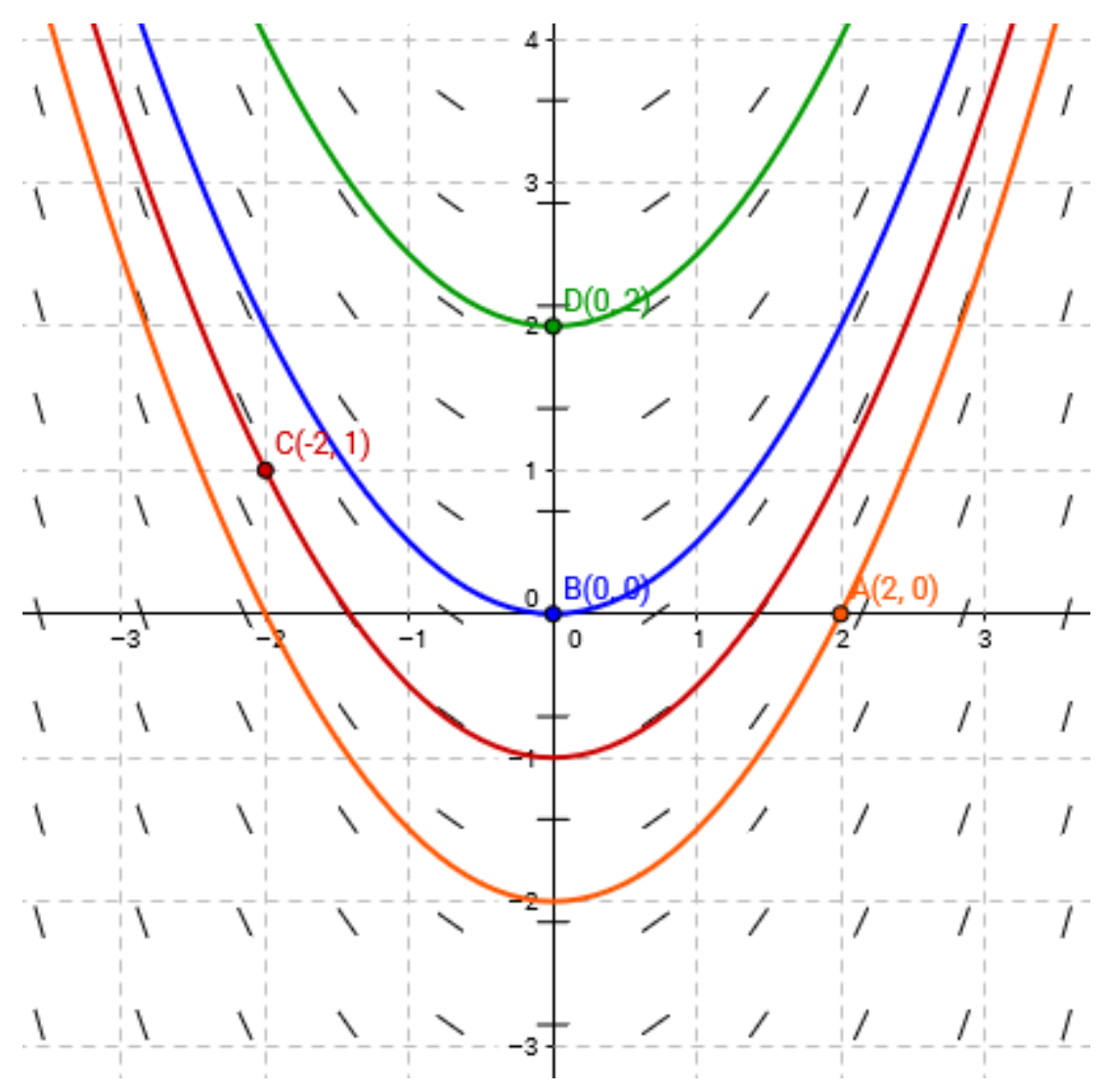

In this case, you could easily have solved the ODE, and obtained $y(x)=\frac{x^{2}}{2}+C$ as the general solution. The four graphs above show solutions for four different values of $C$. The direction field method is at its most useful when it is difficult or even impossible to find analytical solutions to a given ODE. In the remainder of the tutorial, you will work with direction fields in small groups. 


\section{Activity 1}

1. Consider the differential equation $\frac{d y}{d x}=y+2$.

a. Use the table and axes provided to draw a direction field for this ODE. You may divide the work among the members of your group but every student must complete the direction field on their tutorial. There are 121 points to consider (but it's not as nasty as it looks!)
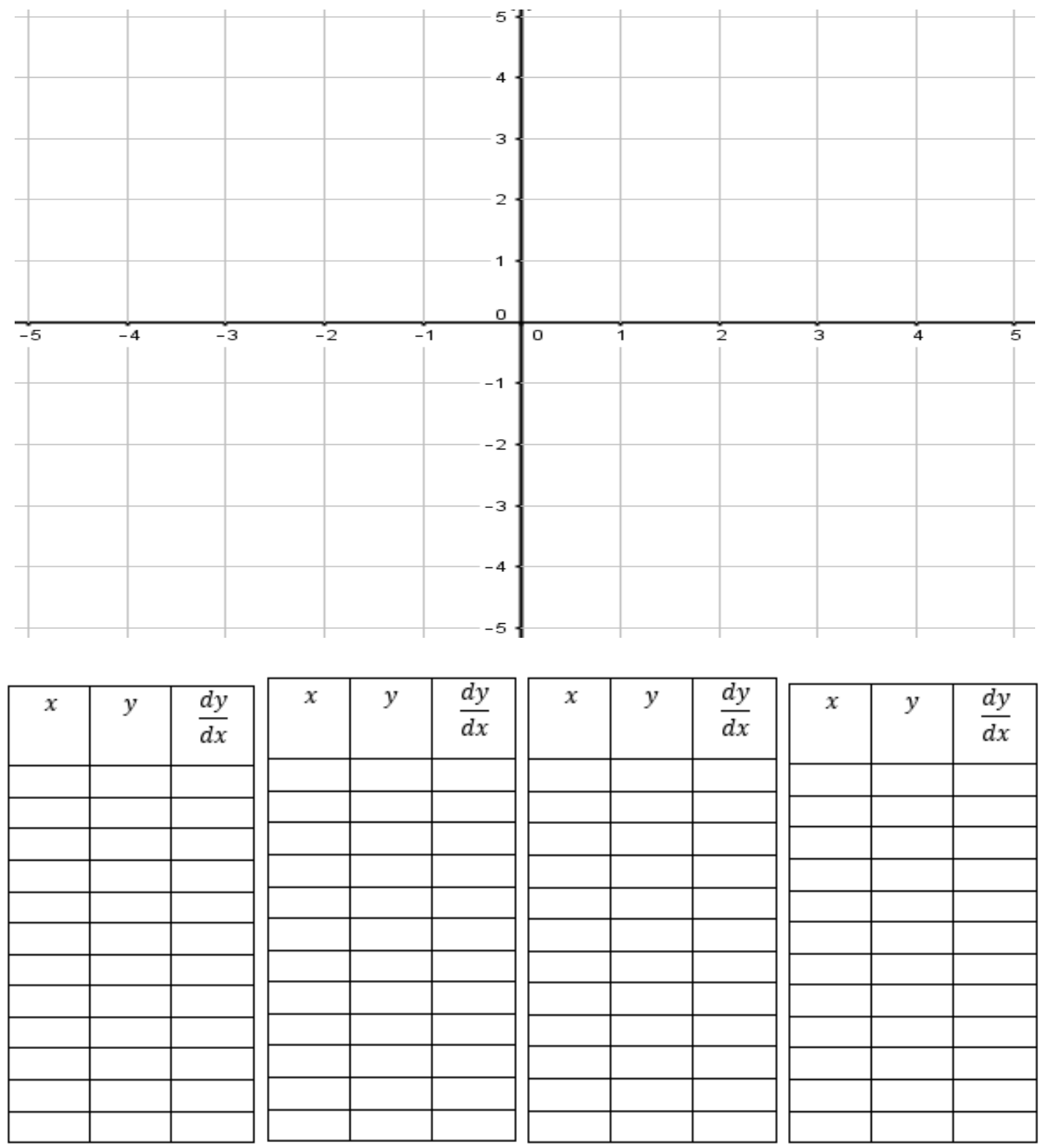

b. How does the value of $x$ affect the slope at each point?

c. Draw the solution to the differential equation that passes through each of the following points: $(0,0) ;(1,-3)$; and $(-2,1)$ on the same diagram as your direction field.

2. Now consider the differential equation $\frac{d y}{d x}=-\frac{x}{y}$.

a. Use the table and axes provided to draw a direction field for this ODE. When you 
have finished your direction field compare it to that of others within your group and resolve any discrepancies.
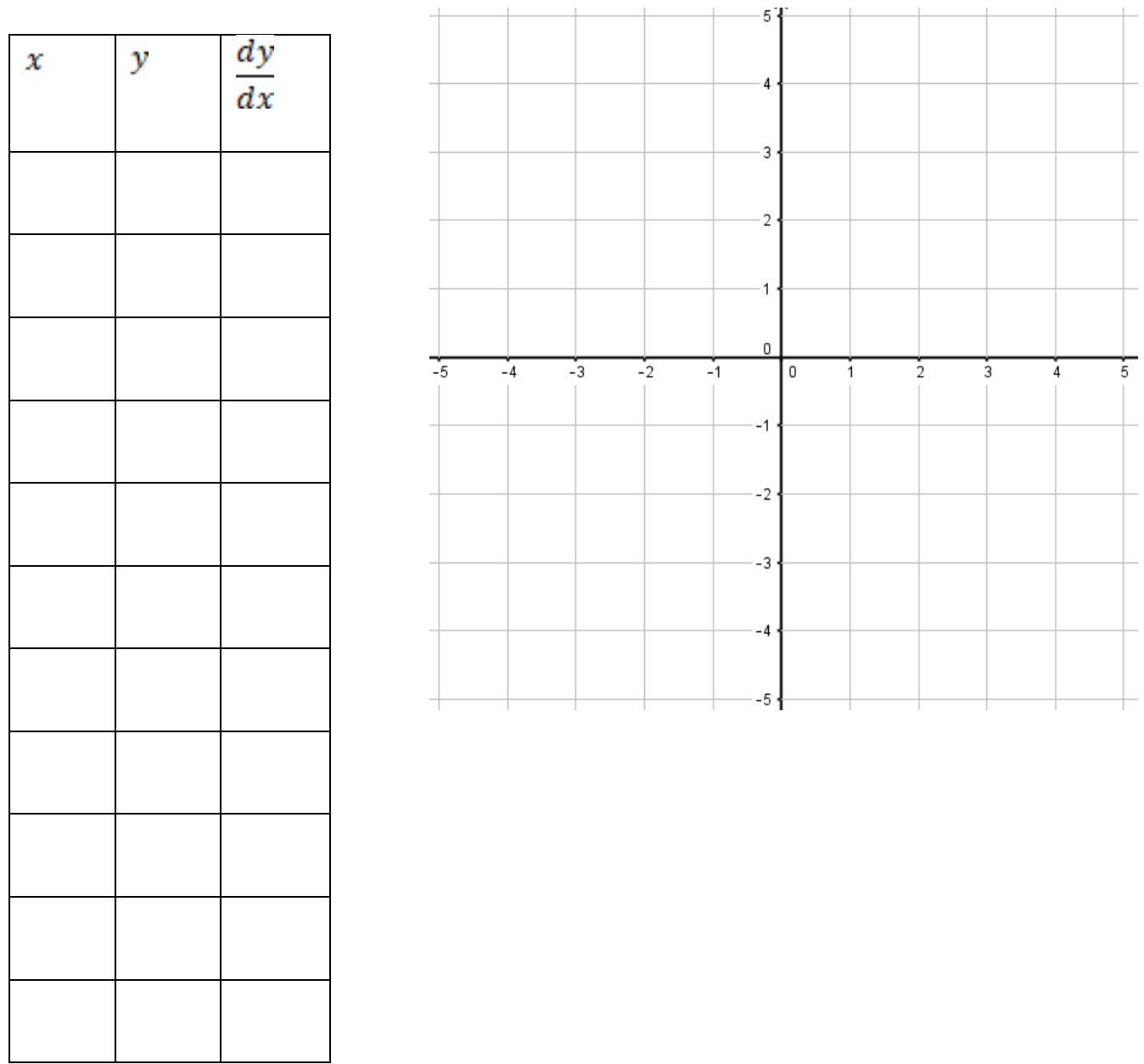

b. Describe the differences between this direction field and the direction field constructed in Question 1. 
3. Which of these differential equations is described in the direction field below?

- $\frac{d y}{d x}=-\frac{x}{y}$;

- $\frac{d y}{d x}=x-y$;

- $\frac{d y}{d x}=y-x$

- $\frac{d y}{d x}=x+y$;

- $\frac{d y}{d x}=\frac{x}{y}$.

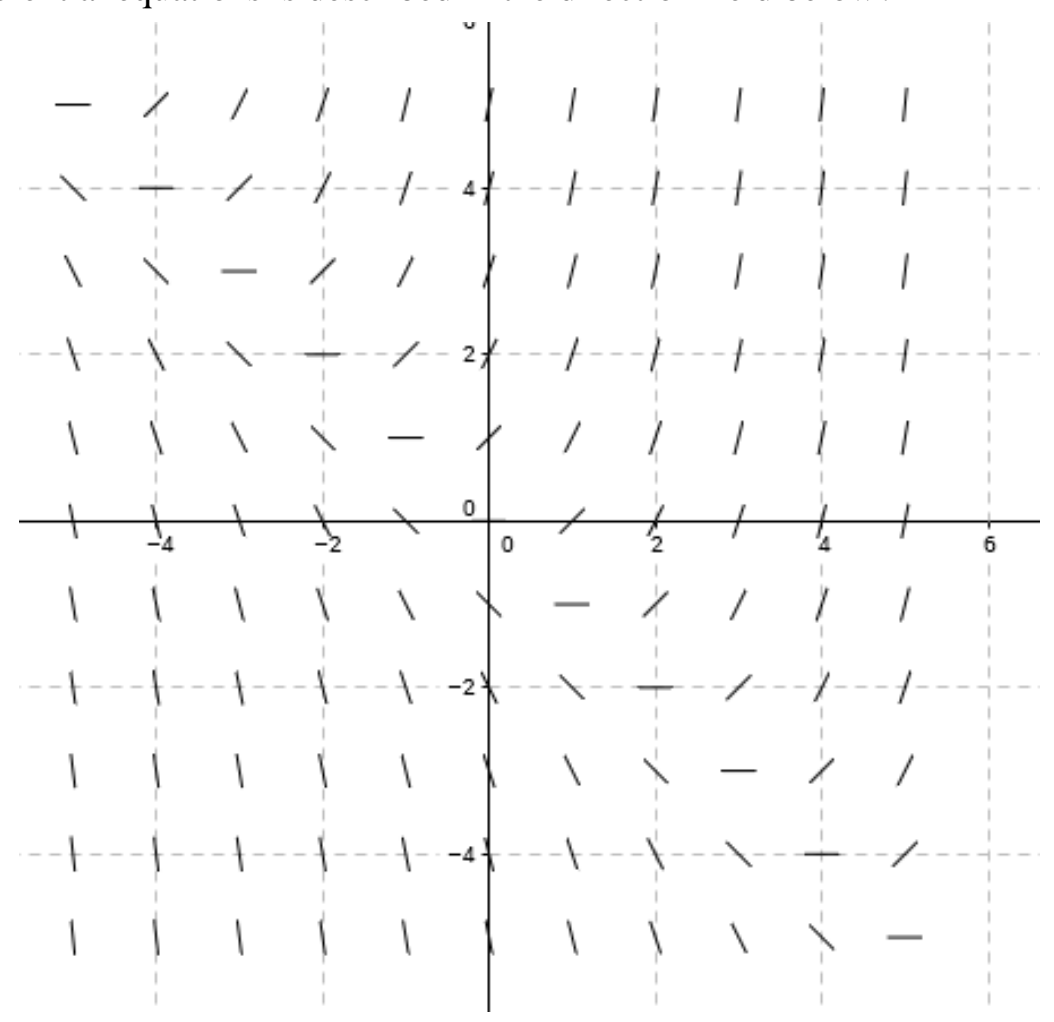

\section{Activity 2}

1. Using the Geogebra file on the MS225 Loop page, construct a direction field with the following properties: the solution curves whose tangents are represented by the direction field

- depend on both $x$ and $y$;

- $\quad$ are increasing for all $x>5$;

- have a vertical asymptote at $x=2$.

\section{Extension Question}

1. Given that $y^{\prime}=\frac{-y}{x^{2}+y^{2}}$ :

a. Sketch the direction field for $-5<x<5,-5<y<5$.

2. Now consider the solution $y(x)$ through $(x, y)=(0,1)$ (i.e. the solution with initial value $y(0)=1)$.

a. Use the direction field plot to show that $y(x)>0$ for $x>0$.

b. Use the analytical form of the ODE to explain that $y(x)$ is decreasing for all $x$.

51. 